\title{
LAS ELECCIONES DE 2004 Y EL LIDERAZGO
}

\section{THE 2004 ELECTIONS AND LEADERSHIP}

David Caldevilla Domínguez: Profesor del Área de Comunicación en la Universidad Complutense de Madrid, la Universidad Europea de Madrid y la Escuela Superior de Estudios de Relaciones Públicas. david.caldevilla@ccinf.ucm.es

\section{CURRÍCULUM VITAE}

Diplomado en Magisterio por la Universidad de Zaragoza (España), licenciado en Comunicación Audiovisual por la Universidad Complutense de Madrid (España). Profesor en la Facultad de Ciencias de la Información de la Universidad Complutense. Secretario General del Fórum Internacional de Comunicación y Relaciones Públicas (España) y autor de varios artículos en revistas universitarias. Director de Operaciones de Imagométrica, s.l. y ex directivo de varias firmas españolas del ámbito de la mercadotecnia.

\section{RESUMEN}

Las elecciones pasadas dejaron una cuestión en el tintero sobre qué influencia habían tenido los atentados del 11 de marzo sobre los votantes. Pero también algo tendría que ver el carisma del líder. Sobre el liderazgo se lleva a cabo un profundo análisis en este artículo. Se distingue entre el liderazgo carismático, el liderazgo autoritario y el liderazgo legal burocrático. Pero son numerosas las tipologías y diferentes las 
perspectivas desde las que se ha estudiado el tema del liderazgo a lo largo del tiempo.

\title{
PALABRAS CLAVE
}

Elecciones - Liderazgo - Carisma - 11 de marzo

\begin{abstract}
The last election left a question on the drawing board on what influence had the March 11 attacks on voters. But it also had something to do the leader's charisma. On Leadership takes a thorough analysis in this article. It distinguishes between charismatic leadership, authoritarian leadership and bureaucratic legal leadership. But there are many types and different perspectives from which we have studied the issue of leadership over time.
\end{abstract}

\section{KEY WORDS}

Elections - Leadership - Charisma - March 11

\section{TEXTO:}

Tras la elecciones generales pasadas, muchos se han planteado qué porcentaje de votos se debe a los luctuosos hechos del 11 de marzo (desgraciada fecha, nefasta, que ya no necesitará el apellido del año porque ya no habrá otro 11 de marzo) y cuál al carisma de un líder o conductor de masas. Buscando por el baúl de los recuerdos, he hallado los estudios de mi juventud en los que se hablaba del liderazgo, hoy tan de 
moda en los cursillos de formación para ejecutivos agresivos ávidos de mejorar sus ratios de gestión y optimizar sus recursos personales.

Retomando lo que de ellos vive en mi memoria, creo entrever imágenes vívidas que pueden muy bien cuadrar con nuestros políticos al uso. Que el lector saque sus propias conclusiones.

En la visión tradicional, Max Weber identificó de manera magistral tres prototipos de liderazgo:

- El liderazgo carismático.

- El liderazgo autoritario.

- El liderazgo legal burocrático.

El tema del liderazgo se aborda desde diferentes perspectivas y se proponen numerosas tipologías. Una de las más conocidas es la ofrecida por Lippit y White, continuadores después de los años 40 de la obra de Lewin. Su clasificación es un punto de referencia obligatorio para cualquier análisis. Según estos autores los líderes se dividen en:

- Autoritarios.

- Paternalistas.

- Laissez-faire ("dejad hacer").

- Democráticos.

- Participativos.

Esta división se hace atendiendo a la manera de: 
Determinar los objetivos del grupo; Tomar las decisiones en el grupo; Tipo de relación entre los miembros del grupo que fomenta el líder; Calidad que se consigue en la realización de las tareas; Participación que se garantiza a los miembros del grupo; Origen y dirección de los flujos de información; Forma cómo se realiza el control; Promociones en el interior del grupo; Quién reparte sanciones y gratificaciones.

Según este análisis, los grupos más eficaces tienen líderes autoritarios, pero su trabajo no alcanza la calidad que consiguen los grupos con líderes democráticos. Las relaciones entre miembros del grupo cambian de forma clara, si se comparan los grupos con líderes paternalistas o democráticos. En el primer caso los miembros abren haces de relación hacia los líderes, en el segundo son los miembros los destinatarios de la interacción. Los flujos de información son pobres en el caso de los grupos paternalistas, se originan casi exclusivamente en la cúspide en los grupos autoritarios y discurren con fluidez en las dos direcciones en los participativos. El control se consigue mediante normas fijadas por el sistema o por los reglamentos internos, en el caso de los líderes paternalista y autoritario, mientras que en los grupos democráticos y participativos existe un autocontrol o el control se lleva a cabo mediante el grupo.

Todos estos son aspectos que revelan la conducta del líder y su influencia en la eficacia del grupo.

Los enfoques modernos del liderazgo nos acentúan la visión política que el lector reconocerá fácilmente:

Modernamente se han acentuado otros aspectos de la conducta del líder (no hay que olvidar que los patrones de conducta del líder son lo que llamamos en lenguaje técnico: estilos de liderazgo). 
1. La dimensión de "consideración" o grado en que el líder tiene en cuenta los sentimientos de los miembros del grupo. Halpin y Winer (1952) indican que cuando esta dimensión tiende a ser alta, el líder se caracteriza por el favorecimiento de la aparición de relaciones personales, muy cordiales, una gran disponibilidad para escuchas a los subordinados y permitir su participación en la toma de decisiones.

2. La dimensión de "iniciativa para la estructura". En este caso el líder facilita y provoca las interacciones en el grupo que tienden a la obtención de las metas del mismo. El líder que se caracteriza por esta conducta asigna a los miembros del grupo tareas concretas y espera que los trabajadores mantengan conductas perfiladas y definidas para la consecución de las metas propuestas.

Es evidente que en el primer caso, los líderes de alta consideración son muy aceptados y logran un clima de distensión y bienestar, mientras que los líderes de iniciación a la estructura consiguen acciones efectivas, pero nunca en un clima grupal distendido.

3. Otras investigaciones, como algunos estudios realizados en la Universidad de Michigan, han distinguido líderes "centrados en los empleados" y líderes "centrados en la producción", con resultados en cuanto a formas de relación y efectividad en el trabajo parecidos a los obtenidos en las investigaciones citadas arriba. Los investigadores de la Universidad de Ohio (EE.UU.) llegaron a la conclusión de que la conducta del líder contenía estas dos dimensiones: la "consideración" y la "iniciativa para la estructura". Estos creen que la falta de consideración no fomenta la satisfacción en el trabajo y la lealtad del empleado. Con estas dos dimensiones produjeron cuatro estilos conductales de liderazgo. 
Se partió inicialmente de la hipótesis de que un estilo de alta estructura y de alta consideración constituirían el mejor estilo de liderazgo. A lo largo de los años, la eficacia del estilo alto-alto ha sido puesta a prueba con mucha frecuencia. En conjunto, los resultados han sido mixtos. De este modo, los investigadores llegaron a la conclusión de que no existe un estilo de liderazgo que pueda considerarse como el mejor. Se arguye, por el contrario, que la eficacia de un determinado estilo de liderazgo dependerá de factores situacionales.

4. La escuela humanista, por su parte, ha estudiado tipos de liderazgo, siguiendo la teoría de McGregor. El líder que se inspira en la teoría X se basa en modelos coercitivos, mecanicistas, económicos, ya que el trabajador detesta el trabajo, no quiere responsabilidades, se mueve por motivaciones crematísticas. En el caso de la teoría Y se produce la integración de los intereses individuales con los objetivos de la organización. Los trabajadores están contentos con las tareas que se les ha encomendado, son responsables, demuestran su capacidad y su experiencia, pierden rango las exigencias económicas.

5. El modelo de contingencia o de la efectividad del liderazgo. Fue desarrollada por Fiedler (1967). Fiedler elaboró la llamada escala del compañero menos preciado (CMA) para identificar los estilos del liderazgo. Fiedler sostiene que la escala CMA indica si un líder tiene un estilo centrado en la tarea o un estilo centrado en las relaciones. Aunque haya habido amplias divergencias en su definición, estos estilos han sido caracterizados de la siguiente manera:

Se cree que las personas con un nivel bajo de CMA, es decir, los que describen al compañero de trabajo menos apreciado en términos negativos, se preocupan primariamente del éxito en su tarea, es decir, están "centrados en la tarea". Por otra parte, a las personas que describen a su compañero de trabajo menos apreciado en términos relativamente positivos (personas con CMA alta) se las considera como 
centradas en las relaciones, es decir, preocupadas espacialmente en conseguir y mantener relaciones interpersonales satisfactorias.

Hoy en día se piensa que el modelo de Fiedler puede necesitar algún refinamiento teórico. Dado que la validez de la escala de CMA está sujeta a dudas, este refinamiento podría suponer una nueva conceptualización del significado del compañero de trabajo menos apreciado.

Dejando aparte la validez de la escala de CMA, el modelo de contingencias de Fiedler ha recibido un amplio respaldo de la investigación. Este hecho implica que la eficacia de la organización puede aumentar si se emparejan apropiadamente líderes y situaciones.

6. La teoría de los "caminos de meta" ha sido propuesta en la década de los 70 por Evans y House. Estos sostienen que los líderes pueden exhibir más de un estilo de liderazgo. En este punto contrastan con Fiedler, que cree que los líderes tienen un estilo dominante. Los cuatro estilos de liderazgo que House y Evans identifican son los siguientes:

Liderazgo directivo: Orienta a los empleados sobre qué debería hacerse y cómo debería hacerse, programando el trabajo y manteniendo los estándares de rendimiento.

Liderazgo de apoyo: Se preocupa por el bienestar y las necesidades de los empleados, mostrándose amigable y asequible a todos y tratando a los trabajadores como iguales.

Liderazgo participativo: Consulta con los empleados y toma en consideración sus ideas al adoptar decisiones. 
Liderazgo centrado en el logro: Estimula al personal a lograr el máximo rendimiento estableciendo objetivos estimulantes, realzando la excelencia y demostrando confianza en las capacidades de sus empleados.

Los resultados de la investigación dan soporte a la idea de que los líderes exhiben más de un estilo de liderazgo.

Llegados a este punto debemos hablar de los factores contingenciales. Estos son variables de situación que hacen que un estilo de liderazgo sea más eficaz que otro. En el contexto actual, estas variables afectan a las percepciones de expectativa o de camino-objetivo. Este modelo presenta dos grupos de variables contingenciales: las características del empleado y los factores ambientales. Las cinco características del empleado más importantes son la localización del control, la capacidad de tarea, la necesidad de logro, la experiencia y la necesidad de claridad. Los tres factores ambientales relevantes son: la tarea del empleado, el sistema de autoridad y el grupo de trabajo. Todos estos factores son capaces de entorpecer o motivar al personal.

La investigación ha dirigido sus esfuerzos a determinar si los diferentes factores contingenciales ejercen alguna influencia en los diversos estilos de liderazgo. Las características del empleado de necesidad de logro, de experiencia y la necesidad de claridad afectaron las preferencias de los empleados respecto al liderazgo.

Para la dirección pueden considerarse tres importantes consecuencias. En primer lugar, los líderes poseen y utilizan más de un estilo de liderazgo. Los gestores, por consiguiente, no deberían dudar en probar nuevas conductas cuando la situación así lo demande. En segundo lugar, los gestores deberían modificar su estilo de liderazgo para adaptarlo a las características de los empleados. Los empleados con alta necesidad de logro, poca experiencia y alta necesidad de claridad deberían ser objeto, 
por lo general, de un liderazgo directivo que aumente su satisfacción y mejore su rendimiento. Por último, el grado de estructuración de la tarea es un factor contingencial importante. Los directivos deberían considerar la utilización de una supervisión de apoyo cuando la tarea sea estructurada. En este contexto, la supervisión de apoyo produce satisfacción, puesto que los empleados ya saben lo que deben hacer.

7. Hay que hacer una referencia al modelo desarrollado por Vroom Yetton (1973). Estudian la conducta del liderazgo de acuerdo con la participación de los miembros de la organización en la toma de decisiones.

8. En el modelo de liderazgo de creación de roles (EVD) George Graen, su creador, cree que las teorías populares sobre el liderazgo se basan en su falso supuesto. Teorías tales como la Red del Liderazgo y el modelo de contingencias de Fiedler suponen que la conducta del líder se caracteriza por un estilo de liderazgo estable y típico. Es decir, estos modelos parten de la hipótesis de que un líder trata a todos sus subordinados prácticamente de la misma manera.

Graen, por el contrario, sostiene que los líderes desarrollan relaciones únicas de persona a persona con cada uno de los individuos que tiene a su cargo. A este tipo de relación los científicos conductistas la denominan diada vertical. Es por ello que al enfoque de Graen se lo conoce como el "modelo de enlace vertical de diadas del liderazgo (EVD)". Se dice que la formación de diadas verticales es un proceso que tiene lugar de manera natural y que resulta del intento de un líder de delegar y de asignar roles de trabajo. Como consecuencia de este proceso, Graen predice que se desarrollará unas relaciones de intercambio entre el líder y los miembros de grupo: intercambio dentro del grupo e intercambio fuera del grupo. 
Si el modelo de Graen es correcto, debería existir una relación significativa entre el tipo de intercambio líder-miembro y los resultados relacionados con el trabajo. La investigación ha confirmado esta predicción.

El modelo EVD de Graen pone de relieve la importancia que reviste el adiestramiento de los gestores en la mejora de las relaciones líder-miembro. En condiciones ideales, se haría así posible tanto la satisfacción en el trabajo como el rendimiento de los empleados, además de disminuir la rotación de personal en la empresa. Aparte del adiestramiento, el investigador de EVD Robert Vecchio ofrece las siguientes sugerencias, tanto para los seguidores como para los líderes, para mejorar la calidad de los intercambios líder-miembro:

Los empleados nuevos deberían ofrecer a su supervisor lealtad, apoyo y disposición para la cooperación.

1. Si uno no es miembro del grupo ha de aceptar su situación y tratar de convertirse en miembro del grupo mostrándose cooperativo y leal. De lo contrario, debería marcharse.

2. Los gestores deberían tratar conscientemente de ampliar sus grupos.

3. Los gestores han de ofrecer a su personal amplias oportunidades de dar pruebas de sus aptitudes.

9. En los últimos años han ido apareciendo nuevas perspectivas en torno a la teoría del liderazgo, a las que se hace referencia como liderazgo "carismático", "heroico", "transformacional" o "visionario". Estas perspectivas, competitivas entre sí pero interrelacionadas, han creado un cierto grado de confusión entre los investigadores y los gestores en ejercicio. Afortunadamente, Robert House y Boas Shamir nos han 
ofrecido una teoría practica e integrada a la que se conoce como liderazgo carismático.

Muchos de los modelos y teorías hasta ahora analizados representan al llamado liderazgo transaccional. El liderazgo transaccional centra su atención en las transacciones interpersonales que se producen entre gestores y empleados. Se considera a los líderes desarrollando conductas que mantienen una interacción de calidad entre ellos mismos y sus seguidores. Las dos características subyacentes al liderazgo transaccional son:

los líderes se sirven de compensaciones contingenciales para motivar a sus empleados y los líderes aplican medidas correctoras sólo en el caso de que sus subordinados no cumplan los objetivos de rendimiento establecidos.

El liderazgo carismático hace hincapié "en la conducta simbólica del líder, en sus mensajes visionarios e inspiradores, en la comunicación no verbal, en el recurso a valores ideológicos, en el estímulo intelectual de los seguidores por parte del líder, en la demostración de confianza en sí mismo y en sus seguidores y en las expectativas que tiene el líder del autosacrificio del seguidor y de su rendimiento más allá de su obligación". El liderazgo carismático puede dar lugar a importantes cambios y resultados en la organización, ya que "transforma" al personal para que procure los objetivos de la organización en vez de sus propios intereses.

Los líderes carismáticos transforman a sus seguidores induciendo cambios en sus objetivos, valores, necesidades, creencias y aspiraciones. Logran esta transformación apelando a los conceptos que sus seguidores tienen de sí mismos, es decir, a sus valores y a su identidad personal. 
Los líderes carismáticos ponen en práctica, en primer lugar, tres conjuntos básicos de conductas del líder. Si lo hacen con eficacia, estas conductas afectan positivamente a los conceptos que de sí mismos tienen los seguidores. A su vez, un concepto positivo de uno mismo impulsa la motivación del empleado hacia una serie de resultados personales, como son el compromiso personal con el líder y con su visión, la conducta de autosacrificio, el compromiso con la organización, la importancia de la tarea y la satisfacción en la misma, la motivación intrínseca y una mejora en el rendimiento.

El primer conjunto de conductas del líder carismático implica establecer una visión común acerca del futuro. Una visión es "un futuro realista, creíble, atractivo para la organización". Según Burt Namus, experto en liderazgo, una visión "correcta" es capaz de desatar el potencial humano, ya que actúa como un faro que guía las esperanzas y el propósito común. Por el contrario, una visión "errónea" puede causar graves daños a una organización.

El segundo conjunto de conductas del líder involucra dos componentes clave:

Los líderes carismáticos crean expectativas y estándares de alto rendimiento porque saben que los objetivos estimulantes y asequibles dan lugar a una mayor productividad.

Los líderes carismáticos necesitan expresar públicamente su confianza en la capacidad de sus seguidores para satisfacer las expectativas de altos rendimientos. Este punto es de gran importancia, ya que es más probable que los empleados se esfuercen por conseguir objetivos difíciles si están persuadidos de que pueden lograr lo que se espera de ellos.

El tercer y último conjunto de conductas del líder implica que él mismo se constituya en modelo de roles. A través de sus acciones, los líderes carismáticos modelan los 
valores, rasgos, creencias y conductas deseadas que son necesarios para hacer realidad su visión.

El líder carismático influye en tres aspectos del concepto que el seguidor tiene de sí mismo:

Acrecienta la motivación del seguidor para el logro y para la consecución de objetivos.

Aumenta la medida en que los seguidores se identifican con los valores del líder, con sus objetivos y aspiraciones y con los intereses colectivos de todos los empleados.

La autoestima y autoeficacia del seguidor se ven realzadas por la conducta del líder carismático.

Por el contrario, los conceptos de sí mismos de los seguidores se ven afectados negativamente por un liderazgo carismático destructivo.

El liderazgo carismático afecta la motivación del empleado. Una de las maneras en que ello tiene lugar es aumentando el valor intrínseco del esfuerzo y de los objetivos del empleado. Los líderes lo consiguen poniendo énfasis en el valor simbólico del esfuerzo: es decir, los líderes carismáticos difunden el mensaje de que el esfuerzo es un reflejo de importantes valores de la organización y de los intereses colectivos. Los seguidores terminan por entender que su nivel de esfuerzo representa una declaración moral.

El liderazgo carismático aumenta también las expectativas de esfuerzo => rendimiento de los seguidores al contribuir de manera positiva a su autoestima y 
autoeficacia. Los líderes elevan también el valor intrínseco del cumplimiento de los objetivos explicando la visión y los objetivos de la organización en función de los valores personales que ellos representan. Los líderes carismáticos aumentan el nivel de significación de las acciones dirigidas al cumplimiento de los objetivos, que da a su vez a los seguidores un sentido de "crecimiento y desarrollo", que representan contribuciones importantes al concepto positivo de uno mismo.

En una revisión recientemente se identificaron 35 estudios empíricos que abarcaban muestras y organizaciones muy diversas. Los resultados señalados que los líderes carismáticos recibieron altas cualificaciones de rendimiento, fueron considerados como líderes más eficaces tanto por sus supervisores como por sus seguidores y tuvieron seguidores más satisfechos y productivos que los líderes no carismáticos. Estos resultados ponen de relieve cuatro importantes implicaciones para la dirección. En primer lugar, los mejores líderes no son simplemente carismáticos, sino que son al mismo tiempo transaccionales y carismáticos. Los líderes deberían intentar asumir estos dos tipos de liderazgo, evitando al mismo tiempo un estilo del tipo "laissezfaire" ("dejar hacer" o "espera y veamos que ocurre"). El liderazgo "laissez-faire" es el estilo más ineficaz de liderazgo.

En segundo lugar, el liderazgo carismático no es aplicable a todas las situaciones que se producen en las organizaciones. Según un equipo de expertos, el liderazgo carismático es más probable que sea efectivo cuando:

La situación ofrece oportunidades para una participación "moral".

Los objetivos de rendimiento no pueden establecerse y medirse con facilidad.

Las recompensas extrínsecas no pueden vincularse claramente con el rendimiento individual. 
Existen pocas señales situacionales o restricciones que guíen la conducta.

Se requiere esfuerzo, conducta, sacrificios y rendimiento excepcionales tanto de los líderes como de sus seguidores.

En tercer lugar, los empleados de cualquier nivel de la organización pueden recibir capacitación para ser más transaccionales y carismáticos. Con ello se refuerza el valor organizativo de desarrollar y desplegar una combinación de capacitación para el liderazgo transaccional y carismático para todos los empleados. En cuarto lugar, los líderes carismáticos pueden ser éticos o faltos de ética. Mientras que los lideres carismáticos éticos dejan que sus empleados acrecienten sus conceptos de sí mismos, los carentes de ética eligen o producen seguidores obedientes, dependientes y complacientes. La alta dirección puede crear y mantener un liderazgo carismático ético:

Creando y poniendo en vigencia un código ético claramente establecido.

Reclutando, seleccionando y promoviendo a personas con una moral y estándares elevados.

Desarrollando expectativas de rendimiento centradas en el trato de los empleados; estas expectativas pueden entonces ser evaluadas en el proceso de valoración del rendimiento.

Capacitando al personal para que sepa valorar la diversidad.

Identificando, compensando y elogiando públicamente al personal que dé ejemplo de una cultura moral elevada. 
En resumen, la teoría clásica ha asignado al líder las siguientes funciones:

1. El líder como ejecutivo: Coordina las tareas del grupo. Supervisa las actividades.

2. El líder como organizador: Planifica, programa, orienta.

3. El líder como estratega: Ordena, distribuye, dispone, arbitra recursos.

4. El líder como experto: Ayuda, aconseja, complementa.

5. El líder como fuente de recompensas y castigo: Premia, censura, reprime.

6. El líder como árbitro y mediador: Ayuda, coopera, motiva, regula.

7. El líder como "portero del grupo": Representa, identifica, avala.

8. El líder como sustituto de la responsabilidad individual.

9. El líder como víctima propiciatoria.

Una vez analizados los elementos anteriores, rogamos al lector puntúe en una escala de 0 a 10 a cada uno de los candidatos y sume el total confrontado. Rodríguez Zapatero es abogado y piensa como tal, es decir, verbalmente; Aznar es economista y su forma de entender el mundo es numérica.

Sea Ferraz o Génova, la suerte de España depende de estas situaciones cotidianas que hacen que la balanza se decante por un platillo u otros, pero siempre dentro del marco que delimita el fiel y los platillos. 
Votar por imagen es votar como se votará en futuro ya que la forma desprovista de su contenido es lo único que nos queda.

Stat rosa pristina nomine, nomina nuda tenemus. (La rosa se mantiene purísima en su nombre (pues sólo) los nombres desnudos nos quedan). A veces el todo es una y la misma cosa. 